\title{
Fracture of the Mandibular Ramus During Third Molar Removal: Case Report
}

\section{Üçüncü Büyük Azı Çekiminde Karşılaşılan Mandibular Ramus Kırığı: Olgu Sunumu}

Ahmet MİHMANLI, Suzan BAYER, Nihat DEMIRTAŞ, Hakkı Oğuz KAZANCIOĞLU

Department of Oral and Maxillofacial Surgery, Bezmialem Vakif University, Faculty of Dentistry, Istanbul, Turkey

\section{ABSTRACT}

Impacted tooth extraction is one of the most common operations in oral surgery. Although practitioners may encounter a variety of complications in the surgical period, mandibular fracture is rare and generally seen during third molar removal. It is reported that possible predisposing conditions include increased age, mandibular atrophy, concurrent presence of cyst or tumor, and osteoporosis. The detection of jaw fractures occurring in tooth extraction may be difficult. Moreover, treatment should be done immediately.

This report presents a case of mandibular fracture that occurred during extraction of a mandibular third molar. In addition, the clinical features and treatment of this rare complication are discussed.

Key Words: Mandibular fracture, extraction, third molar

\section{ÖZET}

Gömülü diş çekimleri, ağız cerrahisinde sıklıkla uygulanan operasyonlardan biridir. Klinisyenler, cerrahi aşamada çeşitli komplikasyonla karşılaşabilmekle birlikte; çene kırıkları, bu ameliyatlarda oldukça nadirdir ve genellikle üçüncü büyük azı dişlerinin çekimleri esnasında görülür. Kırıkların görülmesinde ileri yaş, alt çene atrofisi, büyük bir kist ya da tümör varlığı ve osteoporozün etkili faktörler arasında olduğu bildirilmiştir. Diş çekimi esnasında gözlemlenen çene kırıkların tespit edilmeleri zor olabilir. Ayrıca bu kırıkların tedavilerinin acil olarak yapılması gerekmektedir.

$\mathrm{Bu}$ raporda, yirmi yaş dişi çekimi esnasında gerçekleşmiş bir mandibula kırığı olgusu sunulmuştur. Aynı zamanda, bu nadir komplikasyonun klinik özellikleri ve tedavisi tartışılmıştır.

Anahtar Sözcükler: Mandibula kırı̆̆ı, diş çekimi, üçüncü büyük azı

\section{Giriş}

Alt çene üçüncü büyük azı dişleri, en sık gömülü kalan dişlerdir (1). Enfeksiyon, çürük, kök rezorpsiyonu, kist ve tümör gibi patolojilerin varlığında, bu dişler sıklıkla çekilmektedirler. Klinisyenler bu çekimlerin ardından; alveolit gelişimi, loca absesi, komşu dişlere zarar verilmesi, çenelerde kırık oluşumu, çekilecek dişin anotomik boşluklara kaçırılması, oro-antral fistül oluşumu ve temporomandibular ekleme zarar verilmesi gibi birçok komplikasyon ile karşılaşabilirler (2).

Üçüncü büyük azı çekimlerinde, \%4,6 ile \%30,9 arasında komplikasyon gelişme sıklığı bildirilmiştir (3). Bu komplikasyonlar, minör ya da majör olabilirler ve bazen ameliyat esnasında, bazen de ameliyat sonrası dönemde görülebilirler. Postoperatif komplikasyonlar en sık alveolit, enfeksiyon, kanama ve parestezi olarak bildirilmiştir (1-3). Mandibula kırı̆̆ı, durdurulamayan kanamalar ve dişlerin anatomik boşluklara kaçırılması gibi majör komplikasyonlar, bazen kalıcı hasarlara neden olabilir ve bazen de hastane şartlarında tedavi gerektirebilirler (4). 
a

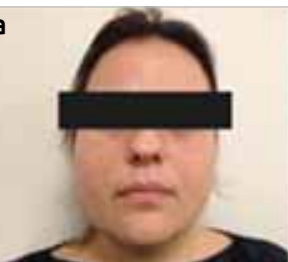

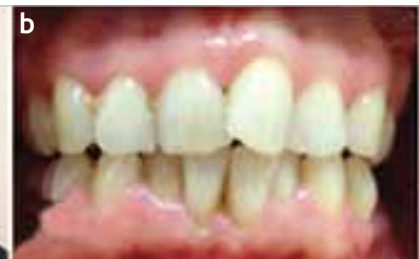

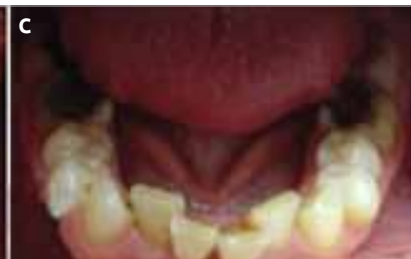

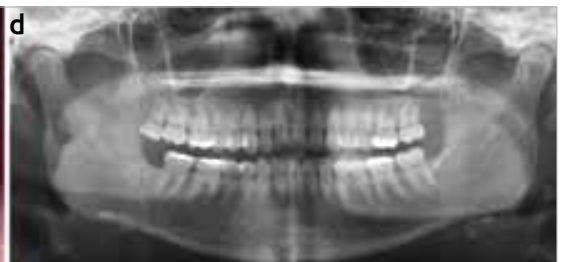

Resim 1. (A) Ekstraoral klinik görünüm (B) Dişler arası oklüzal ilişki (C) Alt çenenin ağı̇ içi görünümü (D) Hastanın panaromik radyografisi
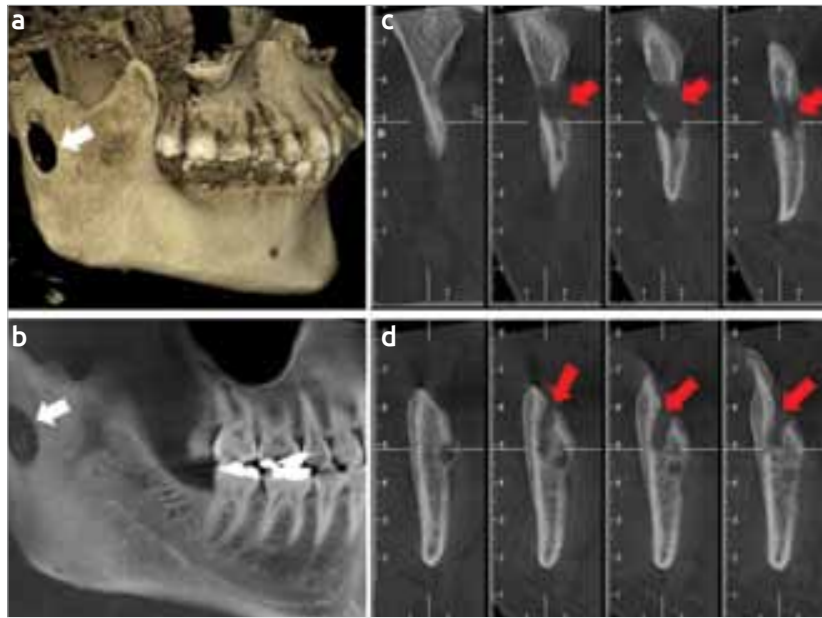

Resim 2. Hastanın dental volumetrik bilgisayarlı tomografi kesitleri $(A, B)$ Sol alt çene ramus bölgesinin üç boyutlu ve panoromik rekonstrüksiyonları; beyaz ok, kortikal destrüksiyonu göstermektedir. (C, D) Sağ ramus mandibulanın çapraz kesit görüntüleri; kırık hattı kırmızı oklarla gösterilmiştir

Mandibula kırığı, genellikle alt üçüncü büyük azı dişlerinin çekimleri esnasında oldukça nadir görülen bir komplikasyondur (5-6). Bu çalışmada, alt çenede yirmi yaş çekimi sırasında gerçekleşen bir kırık olgusunun klinik özelliklerini ve tedavisini sunmak amaçlanmıştır.

\section{Olgu Sunumu}

35 yaşında sistemik olarak sağlıklı bir kadın hasta, iki ay önce sağ alt yirmi yaş dişinin çekilmesinin ardından başlayan şiddetli ağrı ve enfeksiyon şikayetiyle Bezmialem Vakıf Üniversitesi, Diş Hekimliği Fakültesi, Ağız Diş ve Çene Cerrahisi Anabilim Dalı'na başvurmuştur. Hastanın anamnezinde, diş çekiminin oldukça travmatik bir biçimde yapıldığı ve çekim sonrası bölgedeki ağrı ve şişliğin iyileşmediği öğrenilmiştir. Ayrıca çekimin hemen ardından bir süre devam eden krepitasyon hikayesi hasta tarafından bildirilmiştir. Hastanın klinik muayenesinde submandibular bölgede extraoral fistül, sağ yanakta şişlik ve ağız açıklığında kısıtlılık görülmüştür (Resim 1a). Intraoral muayene ve panoromik radyografide dikkat çeken bir özellik gözlenmemiştir (Resim 1 b ve c). Ancak, hastadan, dental volumetrik bilgisayarlı tomografi; (Planmeca ProMax ${ }^{\oplus}$ D; Rosella, USA) alınarak elde edilen üç boyutlu rekonstrüksiyon görüntülerinde, kortikal bölgede perforasyon ve radyolusent bir alanın varlığı görüldü (Resim 2a ve b). Ayrıca çapraz kesitlerde, sağ mandibular ra-
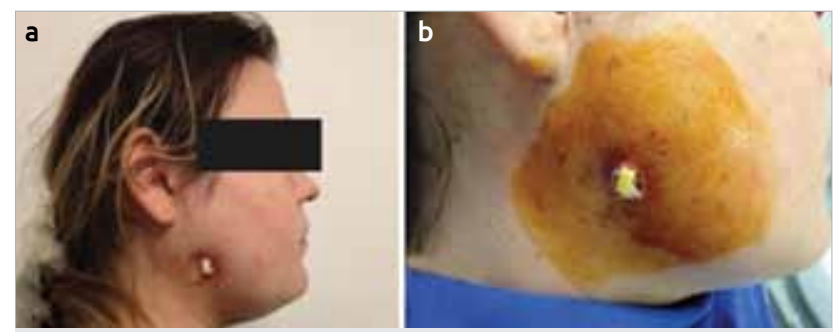

Resim 3. Kırık sonrasında oluşan enfeksiyona bağlı görülen ekstraoral fistül $(A)$ ve tedavide yerleştirilen dren görülmektedir (B)

musta, mandibular kanal üzerinde horizontal olarak seyreden ve iyileşmekte olan bir kırık hattı tespit edildi (Resim $2 \mathrm{c}$ ve d). Klinik ve radyolojik bulgular ile hastadan alınan anamnez doğrultusunda, mandibular ramus kırı̆̆ının diş çekimi esnasında gerçekleştiği düşünülmüştür. Tedavide öncelikli olarak fistül bölgesindeki debridman temizlenerek drenaj sağlanmış ve gün aşırı serum fizyolojik ile debridman yapılmıştır (Resim $3 \mathrm{a}$ ve b). Aynı zamanda iki hafta süreyle hastaya günlük 1000 mg Amoksisilin-klavulanat kombinasyonu tablet olarak verilmiştir. Pansumanların devam ettiği birinci haftada semptomlar hafiflemiş ve ikinci hafta sonunda hastanın şikayetleri tamamen geçmiştir. Tedavi başlangıcından bir ay sonra ağız açıklığının normale döndüğü ve fistülün tamamen iyileştiği görülmüş ve tedavi sonlandırılmıştır.

\section{Tartı̧̧ma}

Üçüncü molar dişi çekimi esnasında mandibular kırığı, $\% 0,0033$ ve $\% 0,0049$ sıklıkta görülen bir komplikasyondur (5). Mandibula fraktürlerinin oluşmasında hastanın cinsiyeti, yaşı, genel sağlık durumu, çiğneme kaslarının hipertofisi gibi bir çok faktör etkilidir (5-6). Bizim olgumuzda gelişen mandibula kırığında, hastada sistemik veya rezorptif bir faktörün etkili olmadığı, ancak mandibula kırığının, diş çekimi sırasında uygulanan aşırı ve kontrolsüz kuvvete bağlı olarak gelişmiş olabileceği düşünülmüştür. Aynı zamanda submandibular locaya ilerleyen enfeksiyonun ve ekstraoral fistül varlığının da görülmesi, çekim soketinden kırık hattına bakteri infiltrasyonunun gerçekleşmiş olabileceğini göstermektedir.

Ameliyat esnasında mandibula kırıkları kadın hastalarda erkek hastalara göre daha sık görülmektedir $(\mathrm{E} / \mathrm{K}=1 / 1,3)$ Postoperatif mandibular kırıklar ise erkek hastalarda daha sık görülmektedir $(E / K=3,9 / 1)$ (5). Özellikle ileri yaşlardaki hastaların gömülü yirmi yaş diş ameliyatları yapılırken, dişin lokalizas- 
yonuna göre kemik kaldırmak ya da dişi bölerek çıkarmak, çekim komplikasyon gelişme riskini azaltmaktadır (7).

Preoperatif dönemde karşılaşılan mandibula kırıklarında, diş çevresinde görülen enfeksiyon, kist ve tümör gibi oluşumların, dekalsifikasyon artışına bağlı olarak kemiği zayıflattığı düşünülmektedir.Ayrıca çiğneme kuvvetlerinin arttığı bruksizm gibi durumlarda kırık riskinin arttığı bildirilmiştir. Kırık sonucu gözlemlenen kronik enfeksiyonlar; başlıca masseter ve medial pterygoid olmak üzere birçok çiğneme kasını etkileyerek trismusa yol açabilmektedir (6).

Szucs ve ark. (8) üçüncü molar diş çekimi esnasında mandibulada oluşan kuvvetleri, sonlu elemanlar metodu yöntemiyle incelemiştir. Çekim esnasında kontrolateral kuvvet uygulanması sırasında ve osteotomi alanın eksternal oblik sırtı içermesi durumunda en çok stresin olduğunu tespit etmişlerdir. Al-Belasy ve ark. (9) 560 hastada yaptıkları çalışmada, gömülü üçüncü büyük azı çekimi sonrası görülen mandibula kırıkları ile çiğneme kuvvetleri arasındaki ilişkiyi incelemişlerdir. Çalışmalarında, bir grup hastaya çekim sonrası çiğneme kuvvetlerini azaltmak amacı ile dört hafta süreli yumuşak diyet önermişler, diğer gruba ise özel bir beslenme önerisinde bulunmamışlardır. Çalışma sonucunda, gömülü alt yirmi yaş dişlerinin çekimi sonrası oluşabilecek kırıklarının önlenmesi için ilave bir uygulamaya gerek olmadığını rapor etmişlerdir.

Kırık tedavisi redüksiyon ve fiksasyon safhalarını içermektedir. Redüksiyon safhasında mevcut dislokasyonun düzeltilmekte, fiksasyonda ise mandibulanın iyileşmesi tamamlanana kadar immobilizasyonu sağlanmaktadır. İnternal fiksasyonun non-rijit, semi-rijit, rijit tipleri vardır ve ligatür, ortodontik ark, miniplak, vida ve akrilik plak kullanılarak yapılabilir (10). Ayrica, fiksasyon indirek olarak yapılabilmektedir. İntermaksiller fiksasyon (IMF), elastik ve teller yardımıyla yetişkinlerde 6-8 hafta uygulanabilir. Mandibula kırıklarında en sık İMF kullanılmaktadır (11). Bizim olgumuzda dislokasyon ya da oklüzyon bozukluğu görülmediği için tedavide redüksiyon ve fiksasyon uygulanmamışır.

\section{Sonuç}

Bu olgu sunumu bizlere, özellikle alt yirmi yaş dişlerinin çekiminde uygulanan kontrolsüz ve aşırı kuvvetlerin, çene kırıklarına yol açabileceğini ve ardından progresif seyreden enfeksiyonlara neden olabileceğini göstermiştir. Oluşan kırıkların tanısında panoramik radyografilerin yeterli olmadığını ve üç boyutlu görüntüleme yöntemlerinin seçilmesi gerektiğini; k1rığa bağlı ekstraoral fistül olgularında ise geniş spektrumlu antibiyoterapi ile birlikte sık aralıklarla debridman yapılmasının faydalı olacağını düşünmekteyiz.

Informed Consent: Written informed consent was obtained from the patients who participated in this case.

Peer-review: Externally peer-reviewed
Author Contributions: Concept - A.M.; Design - N.D.; Supervision - S.B.; Funding - N.D.; Materials - A.M.; Data Collection and/or Processing - S.B.; Analysis and/or Interpretation - N.D., A.M.; Literature Review - N.D., H.O.K.; Writing - S.B.; Critical Review - H.O.K.

Conflict of Interest: No conflict of interest was declared by the authors.

Financial Disclosure: The authors declared that this study has received no financial support.

Hasta Onamı: Bu olguya katılan hastadan, yazılı hasta onamı alınmıştır.

Hakem Değerlendirmesi: Dış bağımsız

Yazar Katkıları: Fikir - A.M.; Tasarım - N.D.; Denetleme - S.B.; Kaynaklar N.D.; Malzemeler - A.M.; Veri Toplanması ve/veya İşlemesi - S.B.; Analiz ve/ veya Yorum - N.D., A.M.; Literatür Taraması - N.D., H.O.K ; Yazıyı Yazan - S.B. ; Eleştirel İnceleme - H.O.K.

Çıkar Çatışması: Yazarlar çıkar çatışması bildirmemişlerdir.

Finansal Destek: Yazarlar bu olgu için finansal destek almadıklarını beyan etmişlerdir.

\section{Kaynaklar}

1. Duarte BG, Assis D, Ribeiro-Júnior P, Gonçales ES. Does the relationship between retained mandibular third molar and mandibular angle fracture Exist? An assessment of three possible causes. Craniomaxillofac Trauma Reconstr 2012; 5: 127-36. [CrossRef]

2. Guerrouani A, Zeinoun T, Vervaet C, Legrand W. A four-year monocentric study of the complications of third molars extractions under general anesthesia: About 2112 Patients. Corporation International Journal of Dentistry 2013; 2013: 1-6. [CrossRef]

3. Bui CH, Seldin EB, Dodson TB. Types, frequencies, and risk factors for complications after third molar extraction. J Oral Maxillofac Surg 2003; 61: 1379-89. [CrossRef]

4. Bouloux GF, Steed MB, Perciaccante VJ. Complications of third molar surgery. Oral Maxillofacial Surg Clin N Am 2007; 19: 11728. [CrossRef]

5. Ethunandan M, Shanahan D, Patel M. Iatrogenic mandibular fractures following removal of impacted third molars: an analysis of 130 cases. British Dental Journal 2012; 212: 179-84. [CrossRef]

6. Chrcanovic BR, Custódio AL. Considerations of mandibular angle fractures during and after surgery for removal of third molars: a review of the literature. Oral Maxillofac Surg 2010; 14: 71-80. [CrossRef]

7. Barbosa-Rebellato NL, Thomé AC, Costa-Maciel C, Oliveira J, Scariot R. Factors associated with complications of removal of third molars: a transversal study. Med Oral Patol Oral Cir Bucal 2011; 16: 376-80. [CrossRef]

8. Szucs A, Bujtár P, Sándor GK, Barabás J.Finite element analysis of the human mandible to assess the effect of removing an impacted third molar. J Can Dent Assoc 2010; 76: a72.

9. Al-Belasy FA, Tozoglu S, Ertas U. Mastication and late mandibular fracture after surgery of impacted third molars associated with no gross pathology. J Oral Maxillofac Surg. 2009; 67: 856-61. [CrossRef]

10. Rahpeyma A, Khajehahmadi S, Barkhori Mehni S. Treatment of mandibular fractures by two perpendicular mini-plates. Iran J Otorhinolaryngol. 2014; 26: 31-6.

11. Bell RB1, Wilson DM. Is the use of arch bars or interdental wire fixation necessary for successful outcomes in the open reduction and internal fixation of mandibular angle fractures? J Oral Maxillofac Surg. 2008; 66: 2116-22. [CrossRef] 